\title{
Does the second ischemic stroke herald a higher proportional risk for cognitive and physical impairment than the first-ever one?
}

\author{
Mohammed Ezzat Elwan, Aktham Ismail Al-emam, Ahmed Nabil Munir and Mostafa Saleh Melake* (i)
}

\begin{abstract}
Background: Post-stroke cognitive and physical disabilities are common sequelae; however, it seems that the second ischemic stroke carries a higher proportional risk more than expected. In this study, we aimed to study second stroke sequelae over first-ever one with regard to cognition and physical competence. This study was conducted on two groups; the first composed of 40 patients with acute first lifetime ischemic stroke, and the second group composed of 40 acute second lifetime ischemic stroke. The study was done at menoufiya university hospitals from August 2017 to August 2018. Modified Rankin Scale (MRS), National Institute of Health Stroke Scale (NIHSS), and MINI-Cog Score, were performed at onset, 2 weeks and 3 months later. In addition, routine lab and neuro-imaging were also done.

Results: Size of infarction is larger in 2nd group $(p<0.001)$, MRS, and NIHSS are significantly higher in 2nd group. Also, there are significant differences between baseline, 2 weeks, and 3 months follow-up in MRS and NIHSS. Mini-Cog scale showed significant difference between the two groups in favor of better cognition in the 1st group. Atrial fibrillation (AF), $p=0.012$ was a significant risk factor in the 1 st group while smoking, $p=0.017$ was the significant risk factor in the 2nd group. Large size stroke was found as independent risk factor in the 2nd group $(p<0.001)$.
\end{abstract}

Conclusions: There are significant cognitive and physical disabilities in the second recurrent ischemic stroke as compared to the first-ever one, and the second stroke tend to be more dangerous and carry more disability.

Keywords: Second stroke, Cognitive disability, Cerebral infarction

\section{Background}

Despite efforts and better control of risk factors, recurrent stroke is still common [1]. Studies show varying recurrence rates, ranging from $7-20 \%$ at 1 year to $16-35 \%$ at 5 years [2]. About one-half of patients who survive acute ischemic stroke (AIS) or transient ischemic attack (TIA) are at increased risk of recurrent stroke

*Correspondence: Drmostafasaleh@yahoo.com

Neuropsychiatry Department, Menoufiya University, Shebin El-Koum, Egypt within a few days or weeks of the initial event, with the greatest risk during the 1st week [3].

Patients who have a TIA have a 10-year stroke risk of $19 \%$ and a combined 10-year risk of stroke, myocardial infarction, and vascular death of $43 \%$ [4]. Recurrent events lead to prolonged hospitalization, worsened functional outcome, and increased mortality [5].

Recurrent AIS has been associated with functional dependence and increased mortality [6] but this remains insufficiently explored. It seems that the second recurrent ischemic stroke is not just another stroke, but it carries much more disabilities and add a cumulative burden on 
cerebral plasticity leading to a magnified cognitive and physical decapacitation. The aim of this study is to define the pattern of disabilities associated with the second stroke in comparison to the first one.

\section{Methods}

This prospective hospital-based comparative study was performed on two groups, each composed of 40 patients admitted to Neurology department, menoufiya university hospitals, from August 2017 to August 2018, informed written consent was taken from participants or their caregivers. Group I comprises first AIS insult and includes 20 males and 20 females, while group II comprises second AIS insult patients and includes 19 males and 21 females. We included patients above 50 years old. Excluded patients were those presented with TIA, severe hepatic or renal impairment, post-stroke aphasia, major psychiatric disorders. Randomization was based on to include all consecutive cases who fulfill inclusion and exclusion criteria being presented by a clinically manifest stroke.

Both groups were subjected to full history taking, complete physical and neurological examination, lab investigations (blood sugar, lipid profile, complete blood picture, liver and renal functions and PT and INR). Physical disability was assessed by Modified Rankin Scale (MRS) [7], National Institutes of Health Stroke Scale (NIHSS) [8], and cognitive function was assessed by the Mini-Cog scale [9]. The above-mentioned scales were performed by the same examiner at admission, 2 weeks and 3 months later.

All data and materials supporting the results are available.

Statistical analysis was done using IBM SPSS software package version 20 (Armon, NY: IBM Corp, USA). Qualitative data were described using number and percent. The Kolmogorov-Smirnov test was used to verify the normality of distribution. Quantitative data were described using range (minimum and maximum), mean, standard deviation and median. Significance of the obtained results was judged at the $5 \%$ level. Chi-square test was used for categorical variables, to compare between different groups. Fisher's exact or Monte Carlo correction was used for correction of Chi-square when more than $20 \%$ of the cells have expected count less than five. Student's $t$-test was used for normally distributed quantitative variables, to compare between two studied groups. ANOVA was used with repeated measures for normally distributed quantitative variables, to compare between more than two periods or stages, and post hoc test (Bonferroni adjusted) for pairwise comparisons. Mann-Whitney test was used for abnormally distributed quantitative variables, to compare between two studied groups. Friedman test was used for abnormally distributed quantitative variables, to compare between more than two periods or stages and post hoc test (Dunn's) for pairwise comparisons.

Table 1 Demographic and risk factors in the studied groups

\begin{tabular}{|c|c|c|c|c|c|c|}
\hline & \multicolumn{2}{|c|}{ Group I $(n=40)$} & \multicolumn{2}{|c|}{ Group II $(n=40)$} & \multirow[t]{2}{*}{ Test of significance } & \multirow[t]{2}{*}{$p$} \\
\hline & No & $\%$ & No & $\%$ & & \\
\hline \multicolumn{7}{|l|}{ Sex } \\
\hline Male & 20 & 50 & 19 & 47.5 & $x^{2}=0.05$ & 0.823 \\
\hline Female & 20 & 50 & 21 & 52.5 & & \\
\hline \multicolumn{7}{|l|}{ Age (years) } \\
\hline Min.-Max & $50-79$ & & $57-79$ & & & \\
\hline Mean \pm SD & $66.93+8.62$ & & $69.37+5.53$ & & $t=1.513$ & 0.135 \\
\hline Median & 67 & & 70 & & & \\
\hline Hypertension & 13 & 32.5 & 12 & 30 & 0.058 & 0.809 \\
\hline DM & 9 & 22.5 & 15 & 37.5 & 2.143 & 0.143 \\
\hline Hypercholesterolemia & 11 & 27.5 & 18 & 45 & 2.650 & 0.104 \\
\hline Coronary heart disease & 18 & 45 & 21 & 52.5 & 0.450 & 0.502 \\
\hline AF & 7 & 17.5 & 0 & 0 & 7.671 & $0.012^{*}$ \\
\hline Cigarette smoking & 8 & 20 & 18 & 45 & 5.698 & $0.017^{*}$ \\
\hline
\end{tabular}

$D M$ diabetes mellitus, $A F$ atrial fibrillation

$x^{2}:$ Chi-square test; $t$ : Student's $t$ test

*: Statistically significant 


\section{Results}

We found that there was insignificant differences between the two groups regarding demographic and risk factors except AF and cigarette smoking (Table 1).

The type of stroke found in both groups was matched either atherothrombotic, cardiac embolic, lacunar, stroke of other causes and stroke of unknown causes $p$-value, 0.223 (Table 2).

Regarding the infarct location found in both groups was matched $p$-value, 0.208 (Table 3 ).
With regard to the size of infarction, we found that there was significant differences between two groups regarding size of infarction as large sized ones were present more in group II $p$-value $<0.001$ (Table 4).

We found also significant differences between two groups regarding MRS in baseline, after 2 weeks and after 3 months $p$-value $<0.001$ as score was higher in second group (Tables 5, 6).

Regarding the NIHSS, we found significant differences between the two groups regarding NIHSS

Table 2 Comparison between the two studied groups according to the etiological subtypes of ischemic stroke

\begin{tabular}{|c|c|c|c|c|c|c|}
\hline \multirow[t]{2}{*}{ Type of ischemic stroke } & \multicolumn{2}{|c|}{ Group I $(n=40)$} & \multicolumn{2}{|c|}{ Group II $(n=40)$} & \multirow[t]{2}{*}{$x^{2}$} & \multirow[t]{2}{*}{$\mathrm{MC}_{p}$} \\
\hline & No & $\%$ & No & $\%$ & & \\
\hline 1. Atherothrombotic & 17 & 42.5 & 22 & 55.0 & 4.364 & 0.223 \\
\hline 2. Cardio embolic & 14 & 35.0 & 15 & 37.5 & & \\
\hline 3. Lacunar & 3 & 7.5 & 2 & 5.0 & & \\
\hline 4. Stroke of other cause & 4 & 15.0 & 1 & 2.5 & & \\
\hline 5. Stroke of unknown causes & 2 & 5.0 & 0 & 0.0 & & \\
\hline
\end{tabular}

$x^{2}$ : Chi-square test; ${ }^{\mathrm{MC}} p$ : Monte Carlo correction

Table 3 Comparison between the two studied groups according to infarct location

\begin{tabular}{|c|c|c|c|c|c|c|}
\hline & \multicolumn{2}{|c|}{ Group I $(n=40)$} & \multicolumn{2}{|c|}{ Group II $(n=40)$} & \multirow[t]{2}{*}{$x^{2}$} & \multirow[t]{2}{*}{$p$} \\
\hline & No & $\%$ & No & $\%$ & & \\
\hline \multicolumn{7}{|l|}{ Infarct location } \\
\hline Frontal infarct & 5 & 12.5 & 5 & 12.5 & 5.397 & ${ }^{M C} C_{p}=0.208$ \\
\hline Occipital infarction & 5 & 12.5 & 4 & 10 & & \\
\hline Capsular infarct & 10 & 25.5 & 15 & 37.5 & & \\
\hline Parieto-occipital & 5 & 12.5 & 5 & 12.5 & & \\
\hline Temporoparietal & 4 & 10 & 4 & 10 & & \\
\hline Temporal infarct & 0 & 0.0 & 1 & 2.5 & & \\
\hline Cerebellar & 3 & 7.5 & 3 & 7.5 & & \\
\hline Parietal infarctions & 8 & 20.0 & 2 & 5.0 & & \\
\hline
\end{tabular}

$x^{2}$ :Chi-square test. ${ }^{M C} p$ : Monte Carlo correction

Table 4 Comparison between the two studied groups according to size of infarction

\begin{tabular}{|c|c|c|c|c|c|c|}
\hline & \multicolumn{2}{|c|}{ Group I $(n=40)$} & \multicolumn{2}{|c|}{ Group II $(n=40)$} & \multirow[t]{2}{*}{$x^{2}$} & \multirow[t]{2}{*}{$p$} \\
\hline & No & $\%$ & No & $\%$ & & \\
\hline \multicolumn{7}{|c|}{ Size of infarction } \\
\hline Small & 25 & 62.5 & 4 & 10.0 & \multirow[t]{3}{*}{$30.187^{*}$} & \multirow[t]{3}{*}{$<0.001^{*}$} \\
\hline Medium & 14 & 35.0 & 19 & 47.5 & & \\
\hline Large & 1 & 2.5 & 17 & 42.5 & & \\
\hline
\end{tabular}

$\mathrm{x}^{2}$ : Chi-square test

*: Statistically significant 
Table 5 Comparison between the two studied groups according to MRS

\begin{tabular}{lllll}
\hline MRS & Group I $(\boldsymbol{n}=\mathbf{4 0})$ & Group II $(\boldsymbol{n = 4 0 )}$ & $\boldsymbol{U}$ & $\boldsymbol{p}$ \\
\hline Baseline & & & & \\
Min.-Max & $0.0-3.0$ & $2.0-5.0$ & $69.0^{*}$ & $<0.001^{*}$ \\
Mean \pm SD & $1.63 \pm 0.81$ & $3.83 \pm 0.90$ & & \\
Median & 2.0 & 4.0 & & \\
After 2 weeks & & & & \\
Min.-Max & $1.0-3.0$ & $2.0-5.0$ & $104.5^{*}$ & $<0.001^{*}$ \\
Mean \pm SD & $1.65 \pm 0.62$ & $3.65 \pm 1.03$ & & \\
Median & 2.0 & 4.0 & & \\
After 3 months & & & & \\
Min.-Max & $0.0-2.0$ & $2.0-5.0$ & $42.0^{*}$ & $<0.001^{*}$ \\
Mean \pm SD & $1.23 \pm 0.58$ & $3.48 \pm 1.01$ & & \\
Median & 1.0 & 3.0 & & \\
\hline
\end{tabular}

U: Mann-Whitney test; MRS: Modified Rankin Scale

*: Statistically significant

in baseline, after 2 weeks and after 3 months $p$-value $<0.001$ as score was higher in second group (Tables 7, 8).

Regarding the MINI COG, we found significant differences between the two groups regarding MINI COG in baseline, after 2 weeks and after 3 months (Tables 9, 10).

\section{Discussion}

In the current study, we aimed to evaluate cognitive impairment and physical disability after second cerebral AIS in comparison with that following the first stroke and studying the risk factors of the recurrent AIS. Forty patients in group I with first stroke and another 40 in group II with second stroke were included.

We found that the type of stroke found in both groups was matched either atherothrombotic, cardiac embolic, lacunar, stroke of other cause and stroke of unknown cause ( $p$-value) 0.223 . Two population-based studies found that recurrences were of the same subtype in almost $90 \%$ of cases $[10,11]$.

De la Cámara and colleagues [12] showed that the type of ischemic stroke was atherothrombotic in $62 \%$ of included in the study and in $34.6 \%$ with recurrent stroke, cardioembolic in $21.5 \%$ and $33.8 \%$, respectively, lacunar in $11 \%$ and $21.8 \%$, respectively, due to a hypercoagulable state in $1 \%$ of patients with first diagnosis, due to nonatherosclerotic vasculopathy in $1 \%, 66.7 \%$, respectively.

A retrospective hospital-based study with a more detailed categorization of stroke subtypes suggested that stroke recurrences in lacunar and hemorrhagic index strokes are often of a different type [13], hence the hypothesis of the multifactorial origin of stroke recurrence [14].

In the current study we found that there was significant differences between two groups regarding the second stroke location to the first one in the second group of patients as different locations (non-stereotyped) present more in group II than the same location (stereotyped) with $(p$-value $)<0.001$. The stereotyped lesions were 2 temporoparietal, 2 frontal, 1 occipital, and 1 capsular infarctions.

In Schaapsmeerders and colleagues [15] study they found that the type of lesion found was either supratentorial stroke in $79.0 \%$, infratentorial stroke in $18.5 \%$ or bilateral in $2.5 \%$.

Table 6 Comparison between the different studied periods according to MRS

\begin{tabular}{|c|c|c|c|c|c|}
\hline \multirow[t]{2}{*}{ MRS } & \multirow[t]{2}{*}{ Baseline } & \multicolumn{2}{|l|}{ After } & \multirow[t]{2}{*}{$\mathrm{Fr}$} & \multirow[t]{2}{*}{$p$} \\
\hline & & 2 Weeks & 3 Months & & \\
\hline \multicolumn{6}{|l|}{ Group I $(n=40)$} \\
\hline Min.-Max & $0.0-3.0$ & $1.0-3.0$ & $0.0-2.0$ & $15.880^{*}$ & $<0.001^{*}$ \\
\hline Mean $\pm S D$ & $1.63 \pm 0.81$ & $1.65 \pm 0.62$ & $1.23 \pm 0.58$ & & \\
\hline Median & 2.0 & 2.0 & 1.0 & & \\
\hline Sig.bet.grps & $p_{1}=0.955, p_{2}=0.049^{*}, p_{3}=0.045^{*}$ & & & & \\
\hline \multicolumn{6}{|l|}{ Group $\|(n=40)$} \\
\hline Min.-Max & $2.0-5.0$ & $2.0-5.0$ & $2.0-5.0$ & $21.0^{*}$ & $<0.001^{*}$ \\
\hline Mean $\pm S D$ & $3.83 \pm 0.90$ & $3.65 \pm 1.03$ & $3.48 \pm 1.01$ & & \\
\hline Median & 4.0 & 4.0 & 3.0 & & \\
\hline $\begin{array}{l}\text { Significance between } \\
\text { groups }\end{array}$ & $p_{1}=0.240, p_{2}=0.019^{*}, p_{3}=0.240$ & & & & \\
\hline
\end{tabular}

Fr: Friedman test; MRS: Modified Rankin Scale

*: Statistically significant 
Table 7 Comparison between the two studied groups according to NIHSS

\begin{tabular}{lllll}
\hline NIHSS & Group I $(\boldsymbol{n = 4 0 )}$ & Group II $(\boldsymbol{n = 4 0 )}$ & $\boldsymbol{U}$ & $\boldsymbol{p}$ \\
\hline Baseline & & & & \\
Min.-Max & $2.0-10.0$ & $6.0-15.0$ & $80.0^{*}$ & $<0.001^{*}$ \\
Mean \pm SD & $4.03 \pm 1.89$ & $9.08 \pm 2.18$ & & \\
Median & 3.0 & 9.0 & & \\
After 2 weeks & & & \\
Min.-Max & $2.0-10.0$ & $7.0-12.0$ & $58.5^{*}$ & $<0.001^{*}$ \\
Mean \pm SD & $3.73 \pm 1.74$ & $8.83 \pm 1.47$ & & \\
Median & 3.0 & 9.0 & & \\
After 3 months & & & & \\
Min.-Max & $2.0-7.0$ & $7.0-10.0$ & $4.0^{*}$ & $<0.001^{*}$ \\
Mean \pm SD & $3.18 \pm 1.17$ & $8.38 \pm 0.95$ & & \\
Median & 3.0 & 8.0 & & \\
\hline
\end{tabular}

NIHSS: National Institute of Health Stroke Scale; U: Mann-Whitney test

*: Statistically significant

In this study, we found that there was significant differences between two groups regarding size of infarction as large sized ones were present more in group II $(p$-value $)<0.001$.

In consistent with our results Khedr and colleagues [16], showed that infarction size was larger in patients with dementia and cognitive impairment and that occurs mainly in recurrent strokes with significant difference $(p$-value $=0.001)$.

In our study, we found that there were significant differences between the two groups regarding MRS in baseline, after 2 weeks and after 3 months $(p$-value $<0.001)$ as score was higher in second group, there were significant differences in MRS in both groups from baseline and after treatment either 2 weeks or 3 months ( $p$-value $<0.001)$.

Ntaios and colleagues [17] proved that embolic stroke of undetermined etiology cumulative probability of recurrence was similar to cardioembolic strokes, but higher than all the other types of non-cardioembolic stroke. These patients had a favorable functional outcome, defined as MRS $\leq 2$ (62.5\%), and compared to patients with cardioembolic strokes (32.2\%). This explains why the MRS score was higher in recurrent patients in our study, more evidence of role of MRS in predicting unfavorable outcome like recurrent cases Long and colleagues [18] found that MRS was significantly higher in elderly patients with stroke which had bad outcome than younger patients $(p$-value $)<0.001$.

In the current study, we found that there was significant differences between the two groups regarding NIHSS in baseline, after 2 weeks and after 3 months ( $p$-value $<0.001)$ as score was higher in second group, there was significant differences in NIHSS in group I, II from baseline and after treatment either 2 weeks or 3 months ( $p$-value $<0.001,0.002)$, respectively. Alemam and colleagues [19] showed that there was there was a highly statistically significant correlation between NIHSS score and outcome of AIS $(p \leq 0.0001)$.

We found that there were significant differences between the two groups regarding MINI COG in baseline, after 2 weeks and after 3 months ( $p$-value 0.033, $<0.001$ ), respectively, there was significant differences in MINI COG in group I, II from baseline and after treatment either 2 weeks or 3 months ( $p$-value $<0.001,0.002)$, respectively.

This goes with Borson and colleagues [20], as they found that MINI COG was sensitive to recurrent stroke

Table 8 Comparison between the different studied periods according to NIHSS

\begin{tabular}{|c|c|c|c|c|c|}
\hline \multirow[t]{2}{*}{ NIHSS } & \multirow[t]{2}{*}{ Baseline } & \multicolumn{2}{|l|}{ After } & \multirow[t]{2}{*}{$\mathrm{Fr}$} & \multirow[t]{2}{*}{$p$} \\
\hline & & 2 weeks & 3 months & & \\
\hline \multicolumn{6}{|l|}{ Group I $(n=40)$} \\
\hline Min.-Max & $2.0-10.0$ & $2.0-10.0$ & $2.0-7.0$ & $27.208^{*}$ & $<0.001^{*}$ \\
\hline Mean \pm SD & $4.03 \pm 1.89$ & $3.73 \pm 1.74$ & $3.18 \pm 1.17$ & & \\
\hline Median & 3.0 & 3.0 & 3.0 & & \\
\hline Sig.bet.grps & $p_{1}=0.288, p_{2}=0.003, p_{3}=0.057$ & & & & \\
\hline \multicolumn{6}{|l|}{ Group ॥ $(n=40)$} \\
\hline Min.-Max & $6.0-15.0$ & $7.0-12.0$ & $7.0-10.0$ & $12.0^{*}$ & $0.002^{*}$ \\
\hline Mean \pm SD & $9.08 \pm 2.18$ & $8.83 \pm 1.47$ & $8.38 \pm 0.95$ & & \\
\hline Median & 9.0 & 9.0 & 8.0 & & \\
\hline $\begin{array}{l}\text { Significance between } \\
\text { groups }\end{array}$ & $p_{1}=0.737, p_{2}=0.049^{*}, p_{3}=0.180$ & & & & \\
\hline
\end{tabular}

NIHSS: National Institute of Health Stroke Scale; Fr: Friedman test

*: Statistically significant 
Table 9 Comparison between the two studied groups according to MINI COG

\begin{tabular}{lllll}
\hline MINI COG & Group I $(\boldsymbol{n}=\mathbf{4 0})$ & Group II $(\boldsymbol{n}=\mathbf{4 0})$ & $\boldsymbol{U}$ & $\boldsymbol{p}$ \\
\hline Baseline & & & & \\
Min.-Max & $0.0-5.0$ & $0.0-4.0$ & $583.0^{*}$ & $0.033^{*}$ \\
Mean \pm SD & $2.88 \pm 1.45$ & $2.23 \pm 1.21$ & & \\
Median & 3.0 & 2.0 & & \\
After 2 weeks & & & \\
Min.-Max & $2.0-5.0$ & $0.0-4.0$ & $369.5^{*}$ & $<0.001^{*}$ \\
Mean \pm SD & $3.43 \pm 0.90$ & $2.23 \pm 1.21$ & & \\
Median & 3.50 & 2.0 & & \\
After 3 months & $3.0-5.0$ & $1.0-4.0$ & & \\
Min.-Max & $3.058 .0^{*}$ & $<0.001^{*}$ \\
Mean \pm SD & $3.95 \pm 0.75$ & $2.55 \pm 1.06$ & & \\
Median & 4.0 & 3.0 & & \\
\hline
\end{tabular}

U: Mann-Whitney test

*: Statistically significant

and any dementia that occurred. This explained why in our study its level was much higher in the recurrent group.

Cao and colleagues [21] investigated 40 young patients with ischemic stroke and assessed other domains and found that language comprehension, reasoning, and verbal memory to be most affected. Processing speed was not assessed in these patients.

There were limitations in this study, such as the short duration of follow-up, the number of patients should be increased in further studies, inclusion of patients as first and second stroke should consider imaging as some clinically presented strokes could have previous silent infarcts which might affect the results, a depression scale should be added, and some risk factors like smoking can be a confounding issue that relates to poorer outcome in the second group.

\section{Conclusions}

There are significant cognitive and physical disabilities in the second recurrent ischemic stroke as compared to the first one.

\section{Abbreviations}

TIA: Transient ischemic attack; AIS: Acute ischemic stroke; PT: Prothrombin time; INR: International normalized ratio; MRS: Modified Rankin Scale; NIHSS: National Institutes of Health Stroke Scale; SPSS: Statistical Package for the Social Sciences; AF: Atrial fibrillation.

\section{Acknowledgements}

We acknowledge the patients and their care givers.

\section{Authors' contributions}

MEE: he designed the work and revised the writings. AIA: he did collection of cases and clinical assessment. ANM: he did the part of discussion and statistical analysis. MSM: he wrote the paper and shared in clinical follow-up of cases. All authors read and approved the final manuscript.

\section{Funding}

None.

Availability of data and materials

All related data are available.

\section{Declarations}

\section{Ethics approval and consent to participate}

Name of the ethics committee (Menoufiya ethics committee) Date of approval; July 2017 (we don't have a specific number for this approval), and informed written consent was taken from the patients and it's considered one of the inclusion criteria.

\section{Consent for publication}

We approve the publication. Regarding data about individual case: Not applicable.

Table 10 Comparison between the different studied periods according to MINI COG

\begin{tabular}{|c|c|c|c|c|c|}
\hline \multirow[t]{2}{*}{ MINI COG } & \multirow[t]{2}{*}{ Baseline } & \multicolumn{2}{|l|}{ After } & \multirow[t]{2}{*}{$\mathrm{Fr}$} & \multirow[t]{2}{*}{$p$} \\
\hline & & 2 weeks & 3 months & & \\
\hline \multicolumn{6}{|l|}{ Group I $(n=40)$} \\
\hline Min.-Max & $0.0-5.0$ & $2.0-5.0$ & $3.0-5.0$ & $25.529^{*}$ & $<0.001^{*}$ \\
\hline Mean \pm SD & $2.88 \pm 1.45$ & $3.43 \pm 0.90$ & $3.95 \pm 0.75$ & & \\
\hline Median & 3.0 & 3.50 & 4.0 & & \\
\hline Sig.bet.grps & $p_{1}=0.402, p_{2}=0.004^{*}, p_{3}=0.131$ & & & & \\
\hline \multicolumn{6}{|l|}{ Group $\|(n=40)$} \\
\hline Min.-Max & $0.0-4.0$ & $0.0-4.0$ & $1.0-4.0$ & $12.0^{*}$ & $0.002^{*}$ \\
\hline Mean \pm SD & $2.23 \pm 1.21$ & $2.23 \pm 1.21$ & $2.55 \pm 1.06$ & & \\
\hline Median & 2.0 & 2.0 & 3.0 & & \\
\hline $\begin{array}{l}\text { Significance between } \\
\text { groups }\end{array}$ & $p_{1}=1.000, p_{2}=0.044^{*}, p_{3}=0.044^{*}$ & & & & \\
\hline
\end{tabular}

Fr: Friedman test

*: Statistically significant 


\section{Competing interests}

The authors declare that they have no competing interests.

Received: 25 June 2021 Accepted: 19 October 2021

Published online: 30 October 2021

\section{References}

1. Lee M, Wu YL, Ovbiagele B. Trends in incident and recurrent rates of first-ever ischemic stroke in Taiwan between 2000 and 2011. J Stroke. 2016;18(1):60-5.

2. Boulanger $M$, Béjot $Y$, Rothwell Peter $M$, Touzé E. Long-term risk of myocardial infarction compared to recurrent stroke after transient ischemic attack and ischemic stroke: systematic review and meta-analysis. J Am Heart Assoc. 2018;7(2):e007267.

3. Arsava EM, Kim GM, Oliveira-Filho J, Gungor L, Noh HJ, Lordelo MJ, et al. Prediction of early recurrence after acute ischemic stroke. JAMA Neurol. 2016;73(4):396-401.

4. Mozaffarian D, Benjamin EJ, Go AS, Arnett DK, Blaha MJ, Cushman M, et al. American Heart Association Statistics Committee; Stroke Statistics Subcommittee. Heart disease and stroke statistics-2016 update: a report from the American Heart Association.

5. Oza R, Rundell K, Garcellano M. Recurrent ischemic stroke: strategies for prevention. Am Fam Physician. 2017;96(7):436-40.

6. Jorgensen HS, Nakayama H, Reith J, Raaschou HO, Olsen TS. Stroke recurrence: predictors, severity, and prognosis The Copenhagen Stroke Study. Neurology. 1997;48(4):891-5.

7. Fish J. Rankin Scale. In: Kreutzer JS, Deluca J, Caplan B, editors. Encyclopedia of clinical neuropsychology. New York: Springer; 2011. https://doi.org/ 10.1007/978-0-387-79948-3_1829.

8. Dunning K. National Institutes of Health Stroke Scale. In: Kreutzer JS, Deluca J, Caplan B, editors. Encyclopedia of clinical neuropsychology. New York: Springer; 2011. https://doi.org/10.1007/978-0-387-79948-3_ 1822.

9. Borson S, Scanlan JM, Brush M, Vitaliano P, Dokmak A. The Mini-Cog: a cognitive "vital signs" measure for dementia screening in multi-lingual elderly. Int J Geriatr Psychiatry. 2000;15:1021-7.

10. Burn J, Dennis M, Bamford J, Sandercock P, Wade D, Warlow C. Long-term risk of recurrent stroke after a first-ever stroke: the Oxfordshire Community Stroke Project. Stroke. 1994;25:333-7.
11. Hankey GJ, Jamrozik K, Broadhurst RJ, Forbes S, Burvill PW, Anderson CS, et al. Long-term risk of first recurrent stroke in the Perth Community Stroke Study. Stroke. 1998;29:2491-500.

12 Cámara De la AG, VaronaArche JF, Vivas PF. Recurrence after a first-ever ischemic stroke development of a clinical prediction rule. J Res Neurol. 2013. https://doi.org/10.5171/2013.264063.

13. Yamamoto $H$, Bogousslavsky J. Mechanisms of second and further strokes. J Neurol Neurosurg Psychiatry. 1998;64:771-6.

14. Lees KR. Multifactorial approach to stroke investigation and prevention. Lancet. 1998;352:923-4.

15. Schaapsmeerders P, Maaijwee NAM, van Dijk EJ, Rutten-Jacobs LC, Arntz RM, Schoonderwaldt HC, et al. Long-term cognitive impairment after first-ever ischemic stroke in young adults. Stroke. 2013;44:1621-8.

16 Khedr EM, Hamed SA, El-Shereef HK, Shawky OA, Mohamed KA, Awad EM, et al. Cognitive impairment after cerebrovascular stroke: relationship to vascular risk factors. Neuropsychiatr Dis Treat. 2009;5:103-16.

17. Ntaios G, Papavasileiou V, Milionis H, Makaritsis K, Vemmou A, Koroboki $E$, et al. Embolic strokes of undetermined source in the Athens stroke registry: an outcome analysis. Stroke. 2015;46(8):2087-93.

18. Long S, Lou Y, Gu H, Guo X, Wang T, Zhu Y, et al. Mortality, recurrence, and dependency rates are higher after acute ischemic stroke in elderly patients with diabetes compared to younger patients. Front Aging Neurosci. 2016:8:142

19. Alemam Al. Comparative study of the prognosis of ischemic cerebral stroke subtypes. J Neurol Res. 2017;7(4-5):80-4.

20. Borson S, Scanlan JM, Chen P, Ganguli M. The Mini-Cog as a screen for dementia: validation in a population-based sample. J Am Geriatr Soc. 2003;51(10):1451-4

21. Cao M, Ferrari M, Patella R, Marra C, Rasura M. Neuropsychological findings in young-adult stroke patients. Arch Clin Neuropsychol. 2007;22:133-42.

\section{Publisher's Note}

Springer Nature remains neutral with regard to jurisdictional claims in published maps and institutional affiliations.

\section{Submit your manuscript to a SpringerOpen ${ }^{\circ}$ journal and benefit from:}

- Convenient online submission

- Rigorous peer review

- Open access: articles freely available online

- High visibility within the field

- Retaining the copyright to your article

Submit your next manuscript at springeropen.com 